\title{
Sex hormones induce insulin resistance in 3T3-L1 adipocytes by reducing cellular content of IRS proteins
}

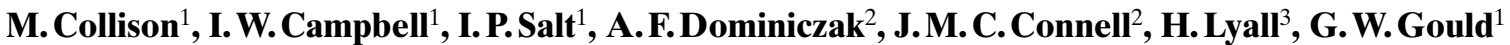 \\ ${ }^{1}$ Division of Biochemistry and Molecular Biology, Davidson Building, Institute of Biomedical and Life Sciences, \\ University of Glasgow, Scotland, UK \\ ${ }^{2}$ University Department of Medicine and Therapeutics, Western Infirmary, Glasgow, Scotland, UK \\ ${ }^{3}$ University Department of Obstetrics and Gynaecology, 10 Alexandra Parade, Royal Infirmary, Glasgow, Scotland, UK
}

\section{Abstract}

Aim/hypothesis. Numerous studies have suggested a relation between sex hormones and insulin sensitivity but the ability of sex hormones to directly influence insulin action in peripheral tissues has not been investigated.

Methods. We have examined the effects of estriol, estradiol and estrone on insulin action in cultured 3T3L1 adipocytes, a useful model of adipocytes.

Results. Treatment of these cells with each of these sex hormones resulted in a statistically significant reduction in the ability of insulin to stimulate glucose transport independently of a reduction in total cellular GLUT-4 content. This diminished ability of insulin to stimulate glucose transport was accompanied by a reduction in the total cellular content of insulin receptor substrates -1 and -2 and the p85 $\alpha$ subunit of phosphatidylinositol 3'-kinase. By contrast, cellular content of protein kinase $\mathrm{B}$ was unchanged by hormone treatment but the magnitude of insulin-stimulated kinase activity was statistically significantly reduced after incubation with each of the sex hormones tested. We have further shown that treatment of 3T3-L1 adipocytes with these hormones alters the subcellular distribution of insulin receptor substrate proteins such that the particulate and soluble pools of these proteins were differentially affected by hormone treatment.

Conclusion/interpretation. These data show that sex hormones can directly induce a state of insulin resistance in 3T3-L1 adipocytes in culture. The mechanism of this defect seems to be at least in part due to decreased cellular content and altered subcellular distribution of insulin receptor substrate proteins which in turn results in a reduction in proximal insulin-stimulated signalling cascades. [Diabetologia (2000) 43: 1374-1380]

Keywords Estradiol, estrone, estriol, insulin resistance, IRS proteins.
Cardiovascular disease in postmenopausal women represents a major health care concern because a third of all women between the ages of 50 and 75 are thought to be affected and a sixth die of the consequences of artherosclerosis. Recent studies have

Received: 23 May 2000 and in revised form: 18 July 2000

Corresponding author: G.W. Gould, Division of Biochemistry and Molecular Biology, Davidson Building, Institute of Biomedical and Life Sciences, University of Glasgow, Glasgow, Scotland G12 8QQ, Scotland, UK

Abbreviations: E1, Estradiol; E2, estrone; E3, Estriol; PI3K, phosphatidylinositol 3'-kinase; IRS, insulin receptor substrate; PKB, protein kinase B; GLUT, glucose transporter. clearly shown a strong correlation between insulin sensitivity and the development of cardiovascular disease [1-3]: thus factors that diminish insulin sensitivity in women have been the subject of considerable interest $[4,5]$. Evidence for an association between sex hormones and insulin sensitivity is provided by studies of women with hyperandrogenic conditions, such as polycystic ovary syndrome [6,7]. These studies have argued strongly for a link between sex hormones and insulin resistance, as an improvement of insulin sensitivity is often observed upon correction of the hyperandrogenism [8-10]. Further correlative evidence for a link between insulin sensitivity and sex hormones is provided by other studies, including the induction of insulin resistance in the surgically 
postmenopausal cynomolgus monkey [11], the development of insulin resistance in anabolic steroid abusers $[12,13]$ and the finding that transsexuals develop insulin resistance in response to either testosterone or ethinyl estradiol treatment [14]. Collectively, such studies suggest that a link exists between sex hormones and peripheral insulin sensitivity [14-16].

Peripheral insulin sensitivity is a function of the ability of insulin to promote glucose uptake into fat and muscle cells. Recent years have seen a considerable growth in our understanding of the mechanism by which insulin stimulates glucose transport in these cells [17-19]. The possibility that sex hormones can modulate peripheral insulin sensitivity by direct action on fat or muscle cells has, however, not been investigated. In this study, we have treated murine 3T3-L1 adipocytes with estradiol (E1), estrone (E2) or estriol (E3) for 12-24 h and studied the consequences of this treatment on insulin sensitivity. We show that treatment with these hormones reduced insulin-stimulated glucose transport by more than $70 \%$ at a maximum dose of insulin. This inhibition of insulin action is accompanied by decreased expression of insulin receptor substrate-1 and -2 (IRS-1, IRS-2) proteins, diminished cellular content of the $\mathrm{p} 85 \alpha$ sub-unit of phosphatidylinositol 3'-kinase (PI3K), and decreased insulin-stimulated protein kinase $\mathrm{B}$ (PKB) activity but no change in total cellular PKB content. Moreover, sex hormone treatment of adipocytes modulates the subcellular distribution of IRS proteins between particulate and soluble fractions, an observation which has previously been postulated as a causative defect leading to insulin resistance in 3T3-L1 adipocytes [18, 20, 21]. Our data show that sex hormones can modulate insulin sensitivity in adipocytes, suggesting that the high circulating concentrations of these hormones observed in some pathophysiological states contribute to the development of insulin resistance by direct action on peripheral tissue.

\section{Materials and methods}

Materials and antibodies. We obtained E1 \{(1,3,5 [10]-Estratriene-3, 17(-diol)\}, E2 (1,3,5 [10]-Estratriene-3-ol-17-one) and E3 \{1,3,5 [10]-Estratriene-3, 16, 17(-diol)\} from Sigma (Poole, UK). Dr G. Danielson (Novo Nordisk, Denmark) generously provided porcine insulin. Anti-IRS-1 antibodies were supplied by Professor K. Siddle (University of Cambridge, UK) and Dr E.M. Gibbs (Pfizer Central Research Groton, Conn., USA). Anti-IRS-2, anti-PKB (PH domain) antibodies and anti-p85 $\alpha$ were from Upstate Biotechnologies (TCS Biologicals, Botolph Claydon, Bucks, UK). Anti-Glut4 was as described previously [22]. All other reagents were as described previously [23-25] or outlined below.

Cell culture and differentiation. We grew 3T3-L1 fibroblasts in $10 \%$ newborn calf serum in DMEM at $37^{\circ} \mathrm{C}$ in $10 \% \mathrm{CO}_{2}$ and passaged at about $70 \%$ confluence. Cells for use in experi- ments were grown in the same medium until 2 days after confluence then differentiated into adipocytes as described [26]. Cells were used between 8-12 days after differentiation and between passages 4 and 12. Cells were incubated with steriod hormones in medium for the times shown in the figure legends. Before use, cell monolayers were washed once with serum-free DMEM then incubated in serum-free DMEM for $2 \mathrm{~h}$.

Deoxyglucose transport assays. Deoxyglucose transport was assayed exactly as outlined in [27]. Cells on six-well plates were incubated in buffer and the transport assay started by the addition of deoxyglucose to a final concentration of $25 \mu \mathrm{mol} / \mathrm{l}$ 2-deoxy-D-glucose $(18.5 \mathrm{kBq} / \mathrm{ml}$ per well $)$. Transport was terminated after 3 minutes by rapid washing in ice-cold buffer. Non-specific cell association of 2-deoxy-D-glucose was measured by parallel assays in the presence of $10 \mu \mathrm{mol} / \mathrm{l} \mathrm{cy-}$ tochalsin B as outlined previously [27].

$P K B$ assay. Cells were treated with the respective hormone overnight, incubated in serum-free DMEM for $3 \mathrm{~h}$ and then incubated without or with insulin for $5 \mathrm{~min}$ and lysed in $50 \mathrm{mmol} / \mathrm{l}$ HEPES, pH 6.5, $150 \mathrm{mmol} / \mathrm{l} \mathrm{NaCl}, 100 \mathrm{mmol} / \mathrm{l} \mathrm{NaF}, 10 \mathrm{mmol} / \mathrm{l}$ sodium pyrophosphate, $1 \mathrm{mmol} / 1$ sodium orthovanadate, $1 \mathrm{mmol} / \mathrm{l}$ EGTA, $1.5 \mathrm{mmol} / 1 \mathrm{MgCl}_{2}, 10 \%$ (v/v) glycerol, $1 \%$ (v/v) Triton-X 100, $10 \mu \mathrm{g} / \mathrm{ml}$ leupeptin, $10 \mu \mathrm{g} / \mathrm{ml}$ leupeptin, $10 \mu \mathrm{g} / \mathrm{ml}$ aprotinin, $10 \mu \mathrm{g} / \mathrm{ml}$ phenylmethylsulphonyl fluoride (PMSF). Lysates were then subject to immunoprecipitation for $2 \mathrm{~h}$ with anti-PKB $\mathrm{PH}$ domain antibodies pre-coupled to protein $\mathrm{G}$ Sepharose beads. After this time immunoprecipitates were washed twice in lysis buffer without Triton-X 100 and then washed and resuspended in kinase buffer containing $50 \mathrm{mmol} / \mathrm{l}$ TRIS, pH 7.6, $10 \mathrm{mmol} / \mathrm{l} \mathrm{MgCl}_{2}, 1 \mathrm{mmol} / \mathrm{l}$ dithiothreitol (DTT). Kinase reaction was initiated by the addition of $50 \mu \mathrm{mol} / \mathrm{l}$ ATP, $108 \mathrm{kBq}\left[\gamma_{-}{ }^{32} \mathrm{P}\right]$ ATP and $30 \mu \mathrm{mol} / \mathrm{l} \mathrm{PKB}$ specific substrate peptide (RPRAATF; gift of Dr R. Plevin, University of Strathclyde, UK) to each tube. After $15 \mathrm{~min}$ at $30^{\circ} \mathrm{C}$, the reaction was stopped by adding $75 \mathrm{mmol} / \mathrm{l}$ orthophosphoric acid. Aliquots were spotted onto squares of P-81 paper, washed twice in $75 \mathrm{mmol} / \mathrm{l}$ orthophosphoric acid, twice in water and then counted.

Plasma membrane lawn assays for GLUT translocation. After experimental manipulations, coverslips of adipocytes were rapidly washed in ice-cold buffer for the preparation of plasma membrane lawns exactly as described previously [24, 25]. Triplicate coverslips were prepared at each experimental condition and ten images of plasma membrane lawns collected at random from each. These were quantified using MetaMorph (Universal Imaging, West Chester, Pa., USA) software.

Preparation of 3T3-L1 adipocyte membranes. We subjected 3T3-L1 adipocytes to a differential centrifugation procedure as described previously [24, 25]. Briefly, cells were scraped and homogenised in ice-cold HES $(20 \mathrm{mmol} / \mathrm{l}$ HEPES, $1 \mathrm{mmol} / \mathrm{l}$ EDTA, $250 \mathrm{mmol} / 1$ sucrose, $\mathrm{pH} 7.4 ; 5 \mathrm{ml}$ per $10 \mathrm{~cm}$ plate) containing protease inhibitors $(1 \mu \mathrm{g} / \mathrm{ml}$ pepstatin $\mathrm{A}$, $0.2 \mathrm{mmol} / \mathrm{l}$ diisopropylfluoro-phosphate, $20 \mu \mathrm{mol} / 1$ L-transepoxysuccinyl-leucylamido-4-guanidinio-butane and $50 \mu \mathrm{mol} / 1$ aprotinin) and the phosphatase inhibitors sordium orthovanadate $(1 \mathrm{mmol} / \mathrm{l})$ and sodium pyrophosphate $(5 \mathrm{mmol} / \mathrm{l})$. Total membranes were prepared by centrifugation of this homogenate at $100,000 \times g$ for $1 \mathrm{~h}$ at $4^{\circ} \mathrm{C}$, the membrane pellet was washed and resuspended in HES buffer containing phosphatase and protease inhibitors and snap frozen in liquid nitrogen and stored at $-80^{\circ} \mathrm{C}$ before use. The supernatant from this fraction (designated as 'soluble protein fraction') was collected and aliquots frozen at $-80^{\circ} \mathrm{C}$ before analysis. 


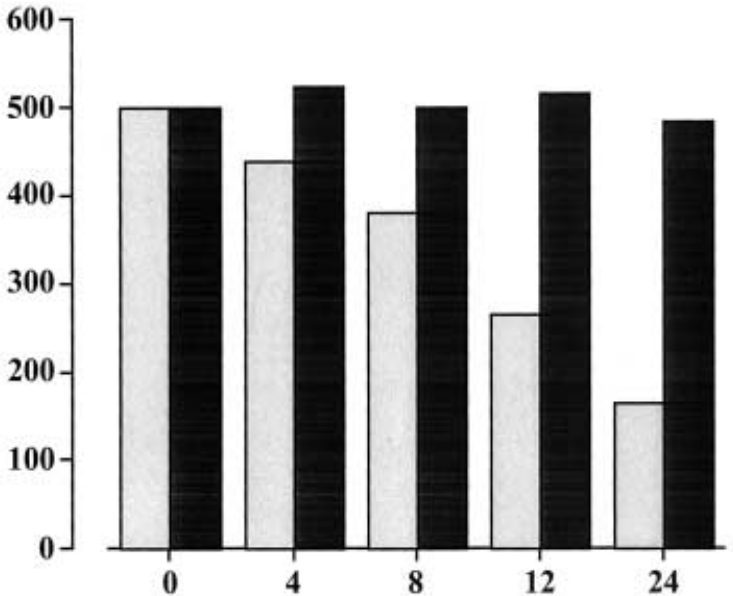

Time of incubation with $\mathrm{E} 1$ (h)

Fig. 1. Time course of the effects of estradiol on insulin-stimulated 2-deoxy-D-glucose transport. 3T3-L1 adipocytes were treated with vehicle or $100 \mathrm{nmol} / \mathrm{l}$ estradiol for the times indicated. After this time, basal and insulin-stimulated 2-deoxy-Dglucose transport rates were measured as described. Shown is data from a typical experiment, repeated twice with similar results. Each point is the mean of triplicate measurements (standard deviation was less than $\pm 10 \%$ at all points). $\square \mathrm{E} 1, \mathbf{V e}$ hicle

SDS-PAGE and immunoblotting. Proteins were resolved by SDS-PAGE on 7,10 or $15 \%$ gels as appropriate and transferred to nitrocellulose membrane as described [24, 25]. Immunolabelled proteins were visualised using HRP-conjugated secondary antibody and the ECL system (Amersham, Amersham, UK). Bands were quantified using a BioRad GS700 system. All immunoblot signals were quantified from linear regions of the protein titration curve [28].

Statistical analysis. Statistical analysis was done using StatView 4 (Abacus, Berkeley, Calif., USA) on a Power Mac. A $p$ value of less than or equal to 0.05 was taken to be a significant difference.

\section{Results}

We set out to examine the effect of sex hormones on insulin sensitivity using the murine 3T3-L1 adipocyte as a model system. We consistently observed that insulin-stimulated deoxyglucose transport was reduced by pretreatment of cells with E1; the effect was statistically significant after about $8 \mathrm{~h}$ of treatment and reached a maximum by $24 \mathrm{~h}$ (Fig. 1 ). The effect reached the maximum at $100 \mathrm{nmol} / \mathrm{l} \mathrm{E} 1, \mathrm{E} 2$ or E3 (data not shown) and therefore this concentration was chosen for all subsequent experiments. We next compared the effect of E1, E2 and E3 on the sensitivity of insulin-stimulated deoxyglucose transport in 3T3-L1 adipocytes, pretreated with these steroids for 12 or $24 \mathrm{~h}$ at $100 \mathrm{nmol} / \mathrm{l}$ in media containing $10 \%$ fetal

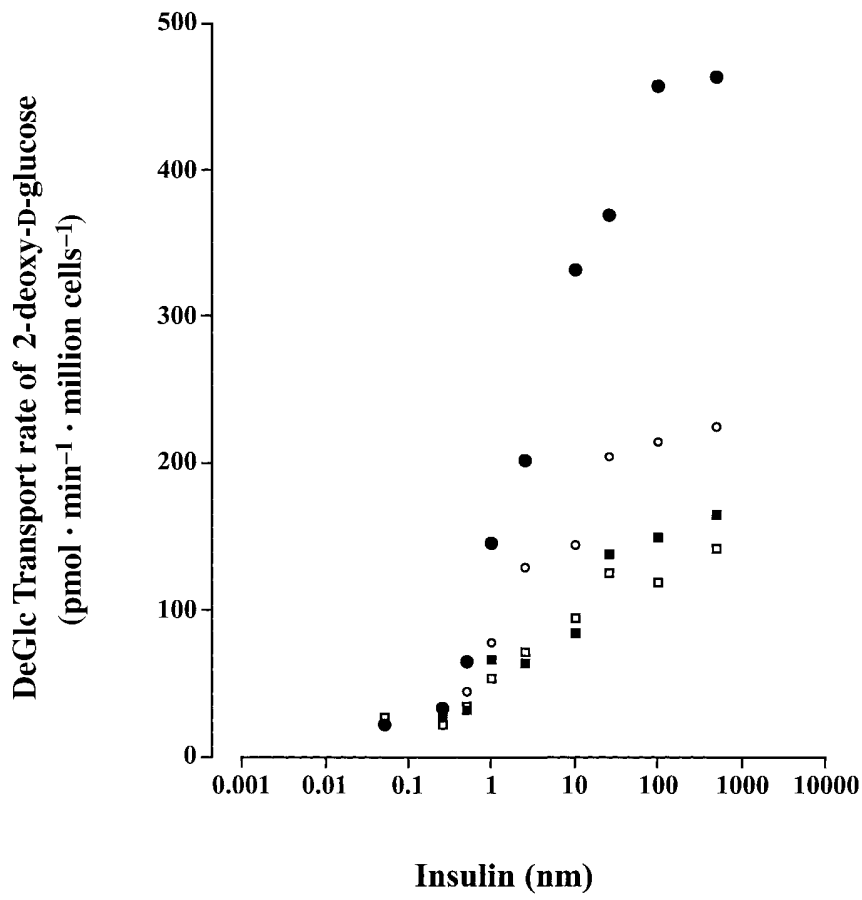

Fig. 2. Dose-response of insulin-stimulated 2-deoxy-D-glucose transport in cells treated with different sex hormones. 3T3-L1 adipocytes were treated with vehicle, E1, E2 or E3 at 100 $\mathrm{nmol} / \mathrm{l}$ for $12 \mathrm{~h}$. Thereafter, insulin-stimulated transport of 2deoxy-D-glucose was measured at a range of insulin concentrations, as shown. In this representative experiment, each point is the mean of triplicate measurements at each concentration of insulin. The experiment was repeated three times with similar results. Similar effects were observed after a 24 -h pre-treatment (data not shown). vehicle, $\square \mathrm{E} 1, \bigcirc \mathrm{E} 2, \square \mathrm{E} 3$

calf serum, compared with cells exposed to the same concentration of vehicle (ethanol). Note that in control experiments, we found that incubation with this concentration of vehicle did not alter the magnitude or sensitivity of insulin-stimulated glucose transport compared with cells not exposed to vehicle (data not shown). Prior incubation of adipocytes with each of these sex hormones induced a diminution of insulinstimulated glucose transport (Fig. 2). Prior incubation with $\mathrm{E} 2$ did not alter the $\mathrm{ED}_{50}$ for insulin-stimulated 2-deoxy-D-glucose transport but incubation with both E1 and E3 resulted in a rightward shift of the $\mathrm{ED}_{50}$ (from $\sim 2 \mathrm{nmol} / \mathrm{l}$ to $\sim 8 \mathrm{nmol} / \mathrm{l}$ ) (Fig. 2 ).

To be certain that the effects observed were manifest at the level of glucose transport and not subsequent metabolism, we assayed insulin-stimulated 3$O$-methyl-D-glucose transport in cells incubated with sex hormones. We found $100 \mathrm{nmol} / \mathrm{l} \mathrm{E} 1$, E2 or E3 reduced the maximum rate of insulin-stimulated 3-Omethyl-D-glucose transport by $60 \%, 51 \%$ and $63 \%$, respectively (data not shown), indicating that this effect reflects an inhibition of transport and not subsequent phosphorylation of deoxyglucose.

We next ascertained whether the observed inhibition of insulin-stimulated glucose transport in re- 

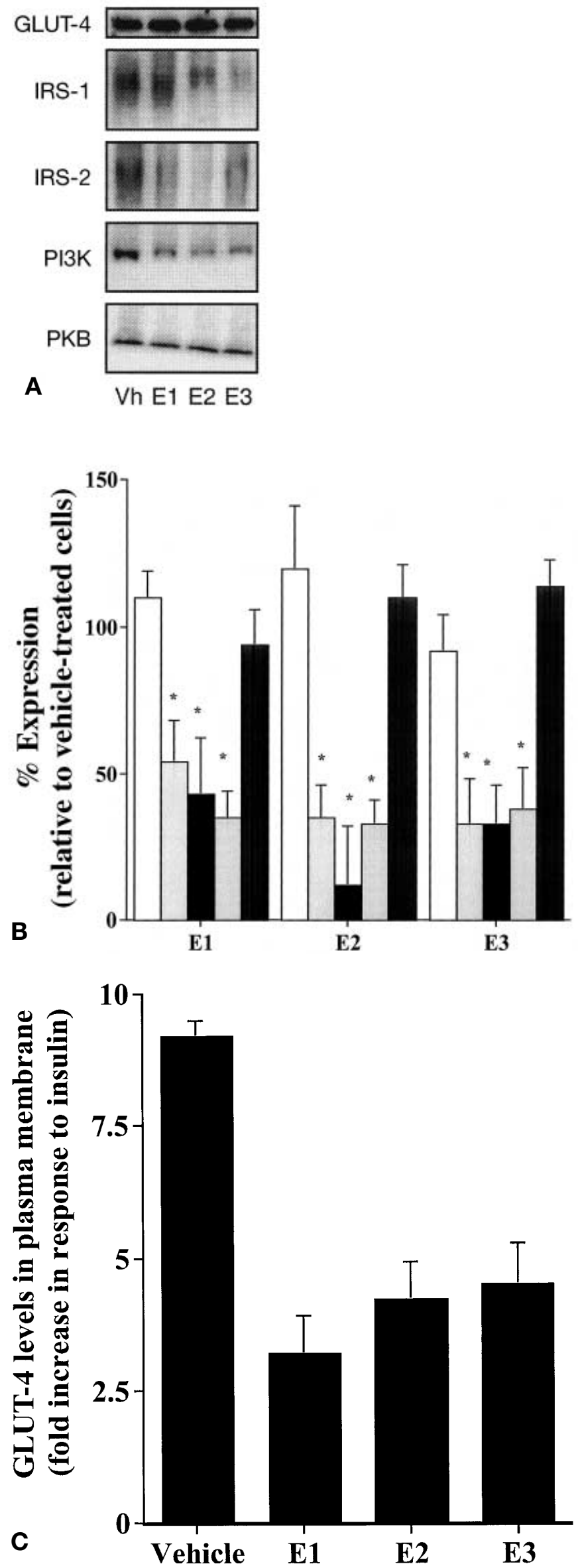

sponse to sex hormones was a consequence of reduced expression of the insulin-responsive glucose transporter, GLUT-4. No significant reduction in cellular GLUT-4 content was observed in total membranes isolated from cells treated with $100 \mathrm{nmol} / \mathrm{l}$ sex hormone for $12 \mathrm{~h}$ (Fig.3A). Plasma membrane lawn assays of GLUT-4 translocation in sex-hormone-treated cells confirmed, however, that insulinstimulated GLUT-4 translocation was reduced by $65 \pm 8 \%$ in E1-treated cells, $54 \pm 8 \%$ in E2-treated cells and $51 \pm 9 \%$ in E3-treated cells $(p<0.05$ in each case) (Fig. 3C).

We next examined the effect of pretreatment with sex hormones on the content of proteins thought to be involved in insulin signal transduction to glucose transport in adipose tissue. Cellular levels of IRS-1, IRS-2 and p85 $\alpha$ were significantly reduced by pretreatment with sex hormones. By contrast, the amount of PKB were unaffected (Fig.3). Protein kinase $\mathrm{B}$ has been proposed to have a crucial role in insulin-stimulated GLUT-4 translocation. Therefore, we assayed the ability of insulin to stimulate PKB activity in cells treated with sex hormone compared with control cells treated with vehicle. The result clearly shows that insulin-stimulated PKB activity is significantly reduced by prior treatment of these cells with sex hormones (Fig. 4).

The subcellular distribution of IRS- 1 and IRS-2 is modulated by insulin [18]. The association of IRS-1 with a cytoskeletal 'scaffold' adjacent to the plasma membrane has been suggested to be a fundamental aspect of insulin signalling in adipocytes [21]. In response to insulin treatment, IRS- 1 is released from this scaffold and seems to behave as a soluble protein, moving from the particulate to the cytosolic fraction upon subcellular analysis [21]. The release of IRS from this intracellular scaffold complex has been proposed to be a crucial causal factor in the development of cellular insulin resistance [20]. We therefore exam-

Fig. 3A-C. GLUT-4 content is not reduced by sex hormone treatment but signalling proteins are decreased. Total cellular content of GLUT-4, IRS-1, IRS-2, p85 $\alpha$ and PKB were measured in lysates of 3T3-L1 cells treated with vehicle (vh) or $100 \mathrm{nmol} / \mathrm{l} \mathrm{E} 1, \mathrm{E} 2$ or E3 for $12 \mathrm{~h}$. A Data from a typical series of immunoblots. B Quantification of three experiments of this type from three different sets of cell lysates (means \pm SD). $\square$ GLUT-4, $\square$ IRS-1, $\square$ IRS-2, $\square$ PI3K, $\square$ PKB. * Significant decrease compared with vehicle control, $p<0.05$. C Data from a typical experiment in which the ability of insulin to stimulate GLUT-4 translocation was assayed using the plasma membrane lawn approach in cells treated as outlined for $\mathbf{A}$. Shown is the data from a typical experiment, repeated twice with quantitatively similar results. Each point is the mean of ten measurements from each of three separate coverslips of plasma membrane lawn $( \pm \mathrm{SD})$. The decrease in insulin-stimulated GLUT-4 translocation in cells treated with sex hormone was statistically significant $(p<0.02)$ for each hormone 


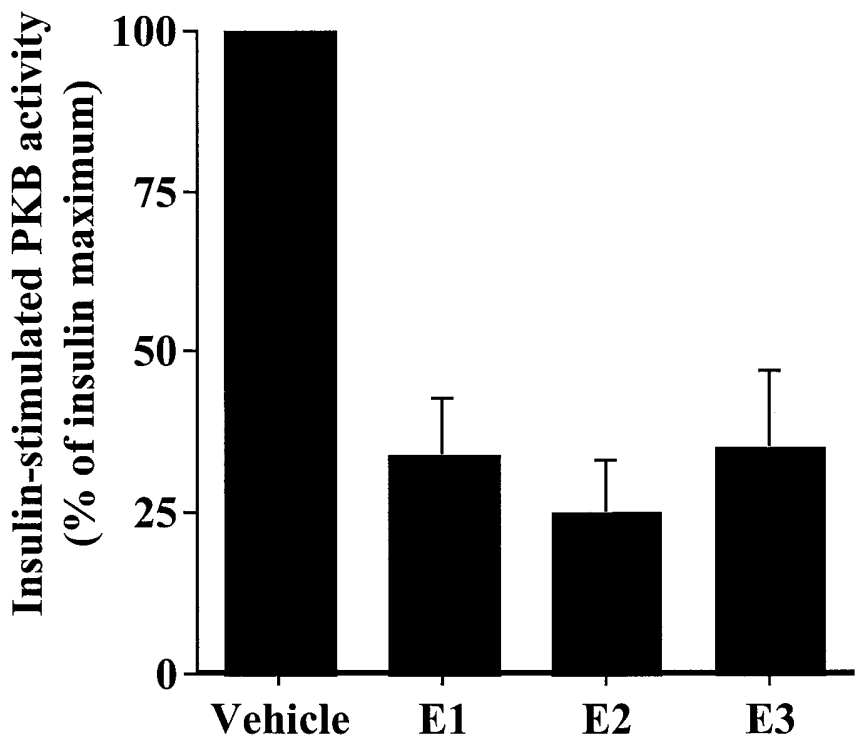

Fig. 4. Insulin-stimulated PKB activity is decreased by treatment with sex hormone. Insulin-stimulated PKB activity was measured in cells incubated for $12 \mathrm{~h}$ with $100 \mathrm{nmol} / \mathrm{l} \mathrm{E} 1, \mathrm{E} 2$ or E3 as outlined in Materials and methods. Insulin (100 nmol/l) was added for $5 \mathrm{~min}$ before lysis and assay. Shown is data from a typical experiment, in which the insulin-stimulated $\mathrm{PKB}$ activity in cells treated with sex hormone is expressed relative to that in vehicle-treated control cells (each point is the mean of triplicate measurements \pm SD). Cells treated with E1, E2 and E3 showed decreased insulin-stimulated PKB activity, in each case the difference was statistically significant, $p<0.04$. Note that basal (un-stimulated) PKB activity was not significantly different between the four groups. Similar effects were observed after a 24 -h pre-treatment (data not shown)

ined the subcellular distribution of IRS-1 and IRS-2 in basal (unstimulated) cells incubated with or without sex hormones for $24 \mathrm{~h}$ and found that the particulate fractions of both IRS-1 and IRS-2 are greatly reduced by prior treatment with sex hormones (Fig.5). In the case of IRS-1, the release from the particulate fraction was paralleled with an increase in the soluble fraction, but IRS-2 protein was observed to decrease in both soluble and particulate fractions in response to treatment with sex hormone.

\section{Discussion}

We have shown in this study that sex hormone treatment of 3T3-L1 adipocytes in culture results in a profound decrease in insulin-stimulated glucose transport, a corresponding decrease in insulin-stimulated GLUT-4 translocation and, in the case of E1 and E3, decreased insulin-sensitivity of insulin-stimulated glucose transport. These data lend support to the notion that circulating sex hormones have a role in the development of insulin resistance associated with certain physiological states including hyperandrogenism and polycystic ovary syndrome $[14,15]$. In these stud-
IRS-1

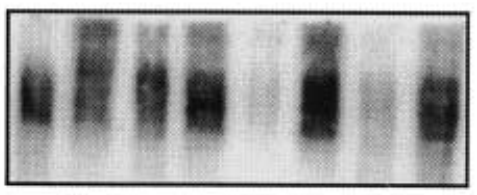

IRS-2

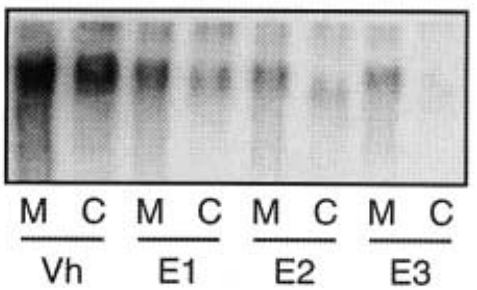

Fig.5. Sex hormones redistribute IRS proteins. Particulate (total membrane) and soluble protein fractions from cells treated with vehicle or $100 \mathrm{nmol} / \mathrm{l} \mathrm{E} 1$, E2 or E3 were analysed by SDS-PAGE and immunoblotting for IRS- 1 and IRS-2. In the immunoblot shown, about $10 \%$ of the particulate material and about $5 \%$ of the soluble protein fraction from a single 10 $\mathrm{cm}$ plate of adipocytes was loaded in each lane. Note that the total protein recoveries in these fractions were not changed by treatment with sex hormone. A representative immunoblot is shown; the experiment was repeated three times with similar results. $\mathrm{M}=$ membrane (particulate) fraction, $\mathrm{C}=$ cytosolic (soluble) fraction

ies cells were exposed to insulin for a single shortterm challenge at a pharmacological dose of steroid; prolonged exposure to lower doses cannot be readily achieved in this model because the cells retain their insulin-sensitive phenotype for only about 5 to 6 days. Thus, the effect of lower (physiological) doses of hormone given long-term could not be determined. Nevertheless, this model provides an attractive system with which to examine changes in the cell biology of insulin action associated with an insulin-resistant-like state.

Insulin signalling involves a complex array of molecules that function in a tightly regulated fashion both spatially and temporally $[18,29,30]$. The activated insulin receptor phosphorylates several target proteins, notably IRS-1 and IRS-2, which function as docking sites for the integration of subsequent cellular responses $[18,29,30]$. One key signal molecule is the enzyme PI3K, because the activity of this enzyme has been shown to be absolutely required for insulinstimulated glucose transport and GLUT-4 translocation [31]. It is proposed that PI3K acts to stimulate GLUT-4 translocation through the kinase PKB [31, 32].

We have shown that the reduction in insulin-stimulated glucose transport observed after treatment with sex hormone arises as a consequence of reduced translocation of GLUT-4 to the plasma membrane, a defect which we found not to be explained by a reduction in cellular GLUT-4 content. This result prompted us to examine the content and activities of signalling proteins known to modulate insulin action and GLUT-4 mobilisation in these cells. Treatment with 
sex hormone resulted in a statistically significant decrease in the cellular content of IRS-1, IRS-2 and the p85a sub-unit of PI3K. The IRS proteins have been shown to have a fundamental role in mediating many of the biological actions of insulin and PI3K is a crucial effector system for insulin in adipose cells. Hence, these data strongly support the notion that the reduced insulin sensitivity observed after treatment with sex hormone is mediated by a loss of the signalling proteins required for effective insulin signal propagation. This thesis is supported by our observation that insulin-stimulated PKB activity is profoundly diminished in hormone-treated cells, although the cellular content of this kinase was not decreased by treatment with sex hormone. This is consistent with the decreased cellular content of key signalling molecules that functionally couple the insulin receptor to PKB. Whether the genes for these signalling molecules are sensitive to sex hormones is still not known.

The question thus arises of how IRS protein content is modulated by treatment with sex hormone. Evidence has been provided which suggests that IRS proteins are enriched in a cytoskeletal fraction that is insoluble in non-ionic detergents and is associated with the particulate fraction of cellular membranes $[18,21]$. Upon insulin-stimulation, both IRS-1and IRS-2 are released from this complex [18, 21]. It has been proposed that this complex provides a platform for the co-localisation of IRS molecules with the insulin receptor and provides a link between IRS proteins and downstream signalling proteins, such as PI3K [21]. Moreover, it has recently been suggested that this complex provides a unique spatial localisation of molecules involved specifically in insulin signalling [20]. This model has recently been extended to show that the release of IRS proteins from this complex into the soluble fraction of the cells could disengage the insulin signalling system and result in a state of insulin resistance [20]. Studies have now shown that chronic insulin treatment of 3T3-L1 adipocytes results in the release of both IRS-1 and IRS-2 from the particulate fraction to the soluble pool and their subsequent degradation, concomitant with the development of insulin resistance in these cells [20]. With this model in mind, we examined the subcellular distribution of IRS-1 and IRS-2 between the soluble and particulate fractions of cells treated with sex hormone. Our data show that treatment with sex hormone for $24 \mathrm{~h}$ resulted in a statistically significant decrease in the particulate IRS- 1 and IRS- 2 content of adipocyte membranes. The soluble pools of IRS-1 and IRS- 2 were also significantly modulated by treatment with sex hormone, such that the soluble fraction of IRS-1 increased but that of IRS-2 decreased. The increased amount of IRS- 1 in the soluble fraction do not account for the loss from the particulate fraction. This is consistent with a model in which release of
IRS proteins from the particulate fraction results in their degradation, thus explaining the observed decrease in cellular IRS protein content in these cells [20].

The link between circulating sex hormones and insulin resistance is well established. Thus, hyperandrogenism and polycystic ovary syndrome are associated with reduced insulin sensitivity. Improvement of androgen excess restores insulin sensitivity, clearly linking the two phenomena. The situation is, however, clearly more complex than a simple association because estrogen deficiency (menopause) is associated with decreased insulin sensitivity. It is likely that these in vivo observations are the consequence of multiple changes in hormonal concentrations and tissue-specific effects. To determine the effect of sex hormones on insulin sensitive tissues directly, here we have examined the effects of a single dose of sex hormone on insulin action in cultured 3T3-L1 adipocytes. We show that treatment with sex hormone at this single dose can reduce statistically significantly insulin sensitivity in these cells. Our data are consistent with a model in which sex hormones modulate insulin sensitivity by decreased expression of IRS proteins. We speculate that this decrease arises, at least in part, by a mechanism involving the release of IRS proteins from a cellular scaffold associated with the particulate fraction of cells. Our data also show that sex hormones can influence insulin sensitivity by direct action on peripheral tissues and thus could be involved in the development of insulin resistance associated with disordered androgen and estrogen metabolism.

Acknowledgements. We thank Professor K. Siddle and Dr E. M.Gibbs for anti-IRS-1 antibodies and Dr R. Plevin for assistance with the PKB assay development. This work was supported by grants from the British Heart Foundation (G.W. Gould and A.F. Dominiczak), the Medical Research Council (Co-operative Group Grant to A.F. Dominiczak, G. W. Gould and J.M.C. Connell), the Mason Medical Research Foundation (H. Lyall) and the Scottish Hospitals Endowments Research Trust (H. Lyall, G. W. Gould and J.M. C. Connell); M. Collison thanks the University of Glasgow Clinical Medicine Planning Unit for studentship.

\section{References}

1. Yip J, Facchini FS, Reaven GM (1998) Resistance to insulin-mediated glucose disposal as a predicator of cardiovascular disease. J Clin Endocrinol Metab 83: 2773-2776

2. Laasko M (1999) Hyperglycaemia and cardiovascular disease in Type II diabetes. Diabetes 48: 937-942

3. Jarrett RJ (1989) Cardiovascular disease and hypertension in diabetes mellitus. Diabetes Metab Rev 5: 547-558

4. Ajabor LN, Tsai CC, Vela P, Yen SSC (1972) Effect of exogenous estrogen on carbohydrate metabolism in postmenopausal women. Am J Obstet Gynecol 113: 383-387

5. Barrett-Connor E, Laakso M (1990) Ischemic heart disease risk in postmenopausal women. Arteriosclerosis 10: 531-534 
6. Dunaif A, Givens JR, Haseltine FP, Meriam GR (1992) The polycystic ovary syndrome. Blackwell Scientific, Cambridge

7. Dunaif A, Segal KR, Futterweit W, Dobrjansky A (1989) Profound insulin resistance independent of obesity in the polycystic ovary syndrome. Diabetes 38 : 1165-1174

8. Dunaif A (1993) Insulin resistance in polycytic ovary syndrome. Ann NY Acad Sci 687: 60-64

9. Godsland IF, Gangar K, Walton C et al. (1993) Insulin resistance, secretion, and elimination in postmenopausal women receiving oral or transdermal hormone replacement therapy. Metabolism 42: 846-853

10. Walton C, Godsland IF, Proudler AJ, Wynn V, Stevenson JC (1993) The effects of the menopause on insulin sensitivity, secretion and elimination in non-obese, healthy women. Eur J Clin Invest 23: 466-473

11. Caefalu WT, Wagner JT, Bell-Farrow AD et al. (1994) The effects of hormone replacement therapy on insulin sensitivity in surgically postmenopausal cynomolgus monkeys (Macaca fascicularis). Am J Obstet Gynecol 171: 440-445

12. Cohen JC, Hickman R (1987) Insulin resistance and diminuished glucose tolerance in powerlifters ingesting anabolic steriods. J Clin Endocrinol Metab 64: 960-963

13. Landon J, Wynn V, Samols E (1963) The effect of anabolic steriods on blood sugar and plasma insulin levels in men. Metabolism 12: 924-928

14. Polerdman KH, Gooren LJG, Asscheman H, Bakker A, Heine RJ (1994) Induction of insulin resistance by androgens and estrogens. J Clin Endocrinol Metab 79: 265-271

15. Shoupe D, Lobo RA (1984) The influemce of androgens on insulin resistance. Fertil Steril 41: 385-388

16. Velazquez EM, Medoza S, Hamer T et al. (1994) Metformin therapy in polycystic ovary syndrome reduces hyperinsulinaemia, insulin resistance, hyperandrogenemia and systolic blood pressure, while facilitating normal menses and pregnancy. Metabolism 43: 647-654

17. Kahn CR (1995) Causes of insulin resistance. Nature 373: 384-385

18. Inoue G, Cheatham B, Emkey R, Kahn CR (1998) Dynamics of insulin signaling in 3T3-L1 adipocytes. J Biol Chem 273: 11548-11555

19. White MF, Kahn CR (1994) The insulin signalling system. J Biol Chem 269: 1-4

20. Clark, S.F., Molero, J.C; James, D. E. (2000) Release of insulin receptor substrate proteins from an intracellular complex coincides with the development of insulin resistance. J Biol Chem 275: 3819-3826

21. Clark SF, Martin S, Carozzi AJ, Hill MM, James DE (1998) Intracellular localisation of phosphatidylinositide 3-kinase and insulin receptor substrate- 1 in adipocytes: potential involvement of a membrane skeleton. J Cell Biol 140: 1211-1225

22. Brant AM, Jess TJ, Milligan G, Brown CM, Gould GW (1993) Immunological analysis of glucose transporters expressed in different regions of the rat brain and central nervous system. Biochem Biophys Res Commun 192: 1297-1302

23. Martin S, Reaves B, Banting G, Gould GW (1994) Analysis of the co-localization of the insulin-responsive glucose transporter (GLUT4) and the trans Golgi network marker TGN38 within 3T3-L1 adipocytes. Biochem J 300: 743-749

24. Millar CA, Sherwan A, Hickson GRX, James DE, Gould GW (1999) Differential regulation of secretory compartments containing the insulin-responsive glucose transporter, GLUT4, in 3T3-L1 adipocytes. Mol Biol Cell 10: 3675-3688

25. Millar CA, Powell KA, Hickson GRX, Bader M-F, Gould GW (1999) Evidence for a role for ADP-ribosylation factor 6 in insulin-stimulated glucose transporter-4 (GLUT4) trafficking in 3T3-L1 adipocytes. J Biol Chem 274: 17619-17625

26. Frost SC, Lane MD (1988) Evidence for the involvement of vicinal sulphydryl groups in insulin-activated hexose transport in 3T3-L1 adipocytes. J Biol Chem 260: 2646-2652

27. Gibbs EM, Lienhard GE, Gould GW (1988) Insulin-induced translocation of glucose transporters to the plasma membrane precedes full stimulation of hexose transport. Biochemistry 27: 6681-6685

28. Maier, V., Melvin, D. R., Lister, C. A., Chapman, H., Gould, G.W; Murphy, G. J. (2000) v- and t-SNARE protein expression in models of insulin resistance: normalisation of glycemia by rosiglitazone treatment corrects over-expression of cellubrevin, VAMP2 and syntaxin 4 in skeletal muscle of Zucker Diabetic Fatty (ZDF) rats. Diabetes 49: 618-625

29. Garvey WT, Birnbaum MJ (1993) Cellular insulin action and insulin resistance. Bailliere's Clin Endocrinol Metab 7: 785-873

30. Saltiel AR (1996) Diverse signalling pathways in the cellular actions of insulin. Am J Physiol 270: E375-E385

31. Shepherd PR, Withers DJ, Siddle K (1998) Phosphoinositide 3-kinase: the key switch in insulin signal transduction. Biochem J 333: 471-490

32. Hill MM, Clark SF, Tucker DF, Birnbaum MJ, James DE, Macaulay SL (1999) A role for protein kinase B/Akt2 in insulin-stimulated GLUT4 translocation in adipocytes. Mol Biol Cell 19: 7771-7781 